\title{
RANCANG BANGUN MESIN PENGERING VERTIKAL DENGAN PENGADUKAN MEKANIK UNTUK BIJI-BIJIAN
}

\author{
Pribadyo \\ Jurusan Mesin, Fakultas Teknik, Universitas Teuku Umar \\ Jl. Alue Peuyareng, Meureubo Aceh Barat 23561 \\ Email: dyo_1806@yahoo.co.id
}

\begin{abstract}
The reduction of water content to a certain extent for cereals in the form of grain can be done through several methods, one of which is drying with heating. The purpose of this research is to design a prototype drying machine with a vertically screw-shaped mechanical screw. The drying machine is designed using heater and mixer working principles, wherein the heater is used for the drying process by engineering the heating air, while the mixer is used for the stirring system on the material to be dried. Tool design includes: Screw, Casing wire, Casing House and chassis. The wire casing design is based on the incoming heat flow rate and exhaust heat flow rate with the parameters of air velocity of entry and exit air velocity is known. The result of air velocity is $0.25 \mathrm{~m}^{2} / \mathrm{s}$ and the air velocity is $0.42 \mathrm{~m}^{2} / \mathrm{s}$. Thus, the incoming heat flow rate is $0.5 \mathrm{~kg} / \mathrm{m}^{3}$, and the outflow heat rate is $0.52 \mathrm{~kg} / \mathrm{m}^{3}$. The volume of the contents of the wire casing of 7,5 kg/ $\mathrm{cm}^{3}$. Screw designed with length (p) $60 \mathrm{~cm}$, width of the upper arm (la) 28.8 $\mathrm{cm}$, width of the forearm (lb) $22 \mathrm{~cm}$. Wire casing is designed with length (p) $100 \mathrm{~cm}$, width of upper arm (la) $50 \mathrm{~cm}$, width of forearm (lb) $30 \mathrm{~cm}$. The casing is designed with length (p) $100 \mathrm{~cm}$, width of the upper arm (la) $70 \mathrm{~cm}$, width of the forearm (lb) $50 \mathrm{~cm}$, The chassis is designed with length (p) $107 \mathrm{~cm}$, width of the upper arm (la) $77 \mathrm{~cm}$ and arm width Bottom (lb) $77 \mathrm{~cm}$. And supported aids in the form of: Electric motor that serves as a driving force in the stirring system with a capacity of $450 \mathrm{rpm}$ motor rotation is reduced with the transmission belt puly. Based on the results of the design has been successfully made prototype vertical dryer machine with mechanical stirring for grain.
\end{abstract}

Keywords: Design, drying machine, screw and mechanical stirrer

\section{PENDAHULUAN}

Pengeringan yang berskala besar sudah tentu tidak dapat lagi dilakukan secara tradisional karena pemakaian cara ini akan sangat memakan banyak waktu, tenaga dan lahan disamping kendala iklim. Oleh karenanya perlu suatu proses buatan untuk tujuan tersebut, yaitu dengan merancang bangun alat pengering. Alat pengering untuk produk hasil pertanian merupakan sarana yang penting dan sangat bermanfaat terutama sekali untuk meningkatkan nilai jualnya, tetapi perlu diketahui bahwa bahan pangan sudah mulai mengalami kerusakan sejak dipanen dan jika tidak segera dicegah maka bahan pangan tersebut menjadi rusak/busuk dan hal itu dapat dicegah salah satu caranya adalah dengan dikeringkan.

Pengeringan merupakan proses sederhana didalam mengurangi kandungan air dari suatu produk/bahan sampai pada tingkat tertentu, sehingga dapat mencegah pembusukan dan aman disimpan dalam jangka waktu yang lama [1]. Kadar air produk harus dikurangi sampai hanya tersisa sekitar 5 sampai 10\% untuk menonaktifkan mikroorganisme yang ada di dalam produk [2]. Umumnya pengeringan dapat dilakukan melalui beberapa metode salah satunya teknologi pengeringan dengan pemanasan yang memanfaatkan energi buatan (mesin pengering) [3].

Saat ini teknologi dari alat-alat pengering telah banyak dikembangkan baik oleh individu, institusi pemerintah maupun pihak swasta mulai dari sistem operasi manual hingga dengan sistem otomatis. Mochammad M.A, 2009 telah membuat mesin pengering dengan menggunakan metode spin dry-pad, yaitu mesin pengering dengan putaran secara horisontal untuk padi berbasis sistem otomatis dengan pengeringan elektrik disertai pengendalian suhu otomatis berkapasitas 10 ton dalam 5 hari yang menggunakan pengeringan paksa.

Namun untuk pengeringan produk hasil pertanian yang berupa biji-bijian mesin pengering yang beroperasi dengan putaran horisontal kurang optimal bila diterapkan karena hasilnya tidak merata dikarenakan bahan akan bertumpuk pada dasar dari wadah dan membutuhkan energi yang besar untuk mengaduknya. Berdasarkan hal tersebut maka rancang bangun mesin pengering vertikal dengan pengadukan mekanik (screw) untuk biji-bijian perlu dilakukan. 


\section{METODE PENELITIAN}

Mesin pengering dirancang berdasarkan metode pengeringan dengan pemanasan menggunakan pengadukan mekanik berupa screw yang bergerak dinamis pada posisi tegak lurus (vertical). Prinsip kerja dari mesin pengering ini adalah heater dan mixer, dimana heater digunakan untuk proses pengeringan dengan merekayasa udara pemanas sedangkan mixer digunakan untuk pengadukan (mixing). Desain rancangan menggunakan Software Autocad 2010.

Komponen utama dari alat yang dirancang bangun meliputi: pengaduk berbentuk Screw, Casing wire, Casing house, rangka (casis) serta komponen bantu lainnya seperti fan, heater, valve, bearing skema komponen alat ditunjukkan pada Gambar 1.

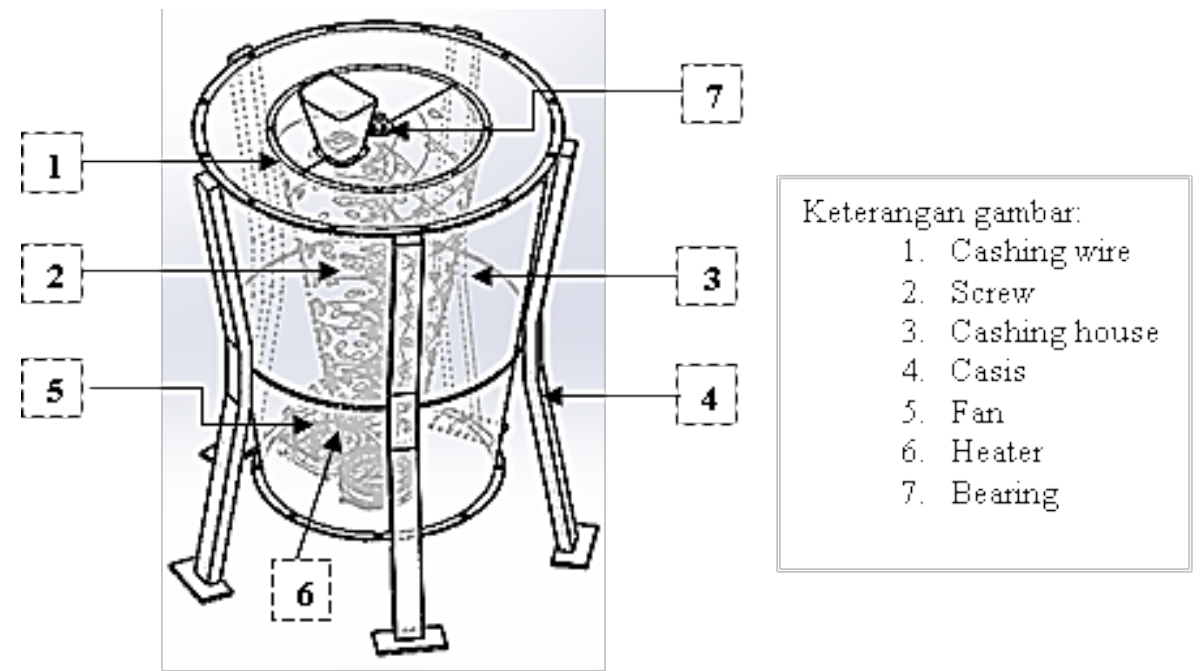

Gambar 1. Skema konstruksi dan komponen alat [10].

Rancangan ruang pemanas didasarkan atas laju aliran panas masuk (flowin) dan laju aliran panas keluar (flow out) dengan parameter kecepatan aliran udara inlet $\left(V_{1}\right)$ dan kecepatan aliran udara outlet $\left(V_{2}\right)$ dari udara pemanas diketahui terlebih dahulu. Kecepatan aliran udara $\left(V_{1}\right)$ dan $\left(V_{2}\right)$ dihitung menggunakan rumus sebagai berikut:

Kecepatan Aliran Udara $\left(V_{1} \& V_{2}\right)$ [4]:

$V_{1}=D_{1} \cdot g$

$V_{2}=D_{1} \sqrt{\frac{2 \cdot g \cdot h}{D_{1}^{2}-D_{2}^{2}}}$

Keterangan :

$D_{1} \quad$ : diameter bawah

$V_{1}$ : kecepatan aliran inlet

$D_{2}$ : diameter atas

$V_{2}$ : kecepatan aliran outlet

$g \quad$ : gaya gravitasi

$h \quad$ : tinggi ruang

Laju aliran panas masuk (flow ${ }_{\text {in }}$ ) dan laju aliran panas keluar (flow out $_{\text {) }}$ dihitung menggunakan rumus sebagai berikut [5]: 
Flow $_{\text {in }}=\rho \cdot A_{1} \cdot V_{1}$

Flow $_{\text {in }}=\rho \cdot A_{2} \cdot V_{2}$

Keterangan :
$\rho:$ : densitas
$V_{1} \quad$ : kecepatan aliran inlet
$V_{2}$ : kecepatan aliran outlet
A : luas penampang

\section{Volume Cashing Wire $\left(V_{w}\right)[4]$ :}

$V_{w}=\frac{1}{3} \cdot \pi \cdot h\left(R^{2}+R \cdot r+r^{2}\right)$

Keterangan :

$$
\begin{array}{lll}
h & : & \text { tinggi ruang } \\
R & : & \text { jari-jari diameter atas } \\
r & : & \text { jari-jari diameter bawah }
\end{array}
$$

\section{Volume Isi Cashing Wire [4]:}

Volume isi casing wire dihitung menggunakan rumus sebagai berikut:

$$
V_{p}=\frac{V_{w}}{A}
$$

Keterangan :

$$
V_{w}: \text { tinggi ruang }
$$

$A \quad$ : luas penampang bahan yang akan dikeringkan

Di subtitusikan ke massa menjadi :

$$
m \cdot V_{p}=k g
$$

Keterangan :

$M \quad$ : masa bahan yang akan dikeringkan

$V_{p} \quad$ : volume bahan yang akan dikeringkan

\section{Pengaduk (Mixing)}

Faktor penting dalam merancang sistem pengaduk pada mesin pengering adalah gradien kecepatan $(G)$ dan waktu pengadukan $(t d)$. Tabel 1 menunjukkan nilai gradien kecepatan $(G)$ dan waktu pengadukan $(t d)$ :

Tabel 1. Nilai gradien kecepatan dan waktu pengadukan [8].

\begin{tabular}{ccc}
\hline No. & $\begin{array}{c}\text { Waktu Pengadukan, } \boldsymbol{t d} \\
\text { (detik) }\end{array}$ & $\begin{array}{c}\text { Gradien Kecepatan, } \boldsymbol{G} \\
\text { (1/detik) }\end{array}$ \\
\hline 1. & 20 & 1000 \\
2. & 30 & 900 \\
3. & 40 & 800 \\
4. & $50 \geq$ & 700 \\
\hline
\end{tabular}




\section{HASIL DAN PEMBAHASAN}

\section{Hasil Perhitungan}

Perhitungan kecepatan aliran udara masuk $\left(V_{1}\right)$;

$$
\begin{aligned}
V_{1} & =D_{1} \cdot g \\
& =0,0254 \mathrm{~m} \cdot 9,81 \mathrm{~m} / \mathrm{s} \\
& =0,25 \mathrm{~m}^{2} / \mathrm{s}
\end{aligned}
$$

Laju aliran panas masuk (Flow in ;

Karena, $P=1$ Atm $=101,35 \mathrm{~Pa}$

$$
\begin{gathered}
A_{1}=\pi \cdot D=3 \cdot 14.0,0254=0,079 \\
P_{\text {absolout }}=P . P_{0}=101,35 \times 10^{5} \cdot 101,35 \times 10^{5}=202,65 \times 10^{5} \\
\quad \rho=\frac{P}{R . T}=\frac{202,65 \times 10^{5}}{287,1 \mathrm{j} / \mathrm{kgk} \cdot 353,15 \mathrm{~K}}=25,94 \mathrm{~kg}
\end{gathered}
$$

maka :

$$
\begin{aligned}
\text { Flow }_{\text {in }} & =\rho \cdot A_{1} \cdot V_{1} \\
& =25,94 \mathrm{~kg} \cdot 0,078 \cdot 0,25 \\
& =0,5 \mathrm{~kg} / \mathrm{m}^{3}
\end{aligned}
$$

Perhitungan kecepatan aliran udara keluar $\left(V_{2}\right)$;

$$
\begin{aligned}
V_{2} & =D_{1} \sqrt{\frac{2 \cdot g \cdot h}{D_{1}^{2}-D_{2}^{2}}} \\
& =0,0254 m \sqrt{\frac{2 \cdot 9,81 \mathrm{~m} / \mathrm{s} \cdot 0,574 \mathrm{~m} / \mathrm{s}}{0,0254^{2}-0.0154^{2} \mathrm{~m}}} \\
& =0,0254 \mathrm{~m} \sqrt{\frac{11,274 \mathrm{~m} / \mathrm{s}}{0,00065-0.00024 \mathrm{~m}}} \\
& =0,0254 \mathrm{~m} \cdot \sqrt{275 \mathrm{~m} / \mathrm{s}} \\
& =0,0254 \mathrm{~m} \cdot 16,58 \mathrm{~m} / \mathrm{s} \\
& =0,42 \mathrm{~m}^{2} / \mathrm{s}
\end{aligned}
$$

Laju aliran panas keluar (Flow out ;

$$
A_{2}=\pi . D_{2}=3.14 \cdot 0,0154=0,048
$$

maka :

$$
\begin{aligned}
\text { Flow }_{\text {out }} & =\rho \cdot A_{2} \cdot V_{2} \\
& =25,94 \mathrm{~kg} \cdot 0,048 \cdot 0,42 \\
& =0,52 \mathrm{~kg} / \mathrm{m}^{3}
\end{aligned}
$$

Perhitungan volume Cashing Wire $\left(V_{w}\right)$;

$$
\begin{aligned}
V_{w} & =\frac{1}{3} \cdot \pi \cdot h\left(R^{2}+R \cdot r+r^{2}\right) \\
& =\frac{1}{3} \cdot 3 \cdot 14 \cdot 100 \mathrm{~cm}\left(12,5 \mathrm{~cm}^{2}+7,5 \mathrm{~cm}^{2}+12,5 \mathrm{~cm} \cdot 7,5 \mathrm{~cm}\right)=104,7 \cdot 306,25 \mathrm{~cm} \\
& =32064,4 \mathrm{~cm}^{3}=104,7 \mathrm{~m}^{3}
\end{aligned}
$$

Perhitungan volume isi Cashing Wire (per satuan biji pinang); 
Diasumsikan massa biji pinang $(m)$ adalah 12.5 gram, sedangkan luas penampang biji pinang $(A)$ adalah sebesar $531 \mathrm{~mm}^{3}$

Maka :

$$
\begin{aligned}
V_{p} & =\frac{V_{w}}{A} \\
& =\frac{32064,4 \mathrm{~cm}^{3}}{53,1 \mathrm{~cm}^{3}} \\
& =603,9 \mathrm{~cm}^{3}
\end{aligned}
$$

Di subtitusikan ke massa menjadi :

$$
\begin{aligned}
m \cdot V_{p}=\mathrm{kg} & \\
12,5 \mathrm{~g} \cdot 603,9 \mathrm{~cm}^{3} & =7548,7 \mathrm{~g} / \mathrm{cm}^{3} \\
& =7,548 \mathrm{~kg} / \mathrm{cm}^{3}
\end{aligned}
$$

\section{Hasil Rancangan Gambar \\ Pengaduk (mixing)}

Sistem pengadukan pada mesin pengering yang dirancang termasuk dalam kategori jenis pengadukan lambat dimana garadien kecepatan kurang dari 100 per detik selama 10 hingga 60 menit (Tabel1). Dimensi screw dengan panjang $(p) 60 \mathrm{~cm}$, diameter lebar atas $\left(l_{a}\right) 28,8 \mathrm{~cm}$, diameter lebar bawah $\left(l_{b)} 22 \mathrm{~cm}\right.$.

\section{Casing wire}

Dimensi casing wire adalah panjang $(p) 100 \mathrm{~cm}$, diameter lebar atas $\left(l_{a}\right) 50 \mathrm{~cm}$, diameter lebar bawah $\left(l_{b}\right) 30 \mathrm{~cm}$. Hasil rancangan desain pengaduk (mixing) dan casing wire ditunjukkan pada Gambar 2 dan 3 di bawah ini:

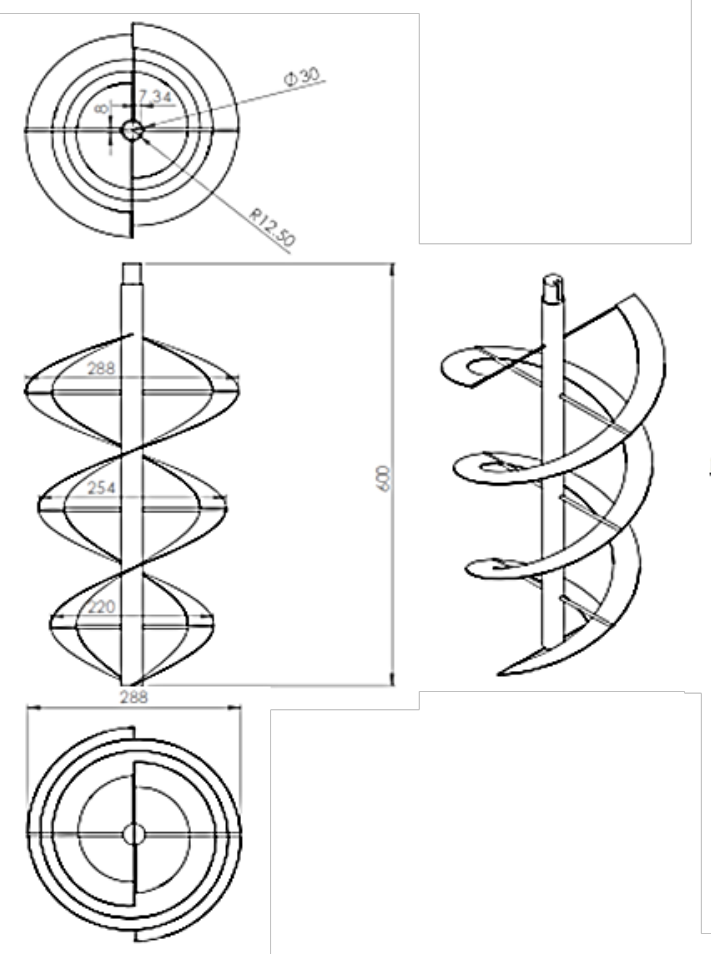

Gambar 2. Desain Pengaduk (Screw) Casing House.
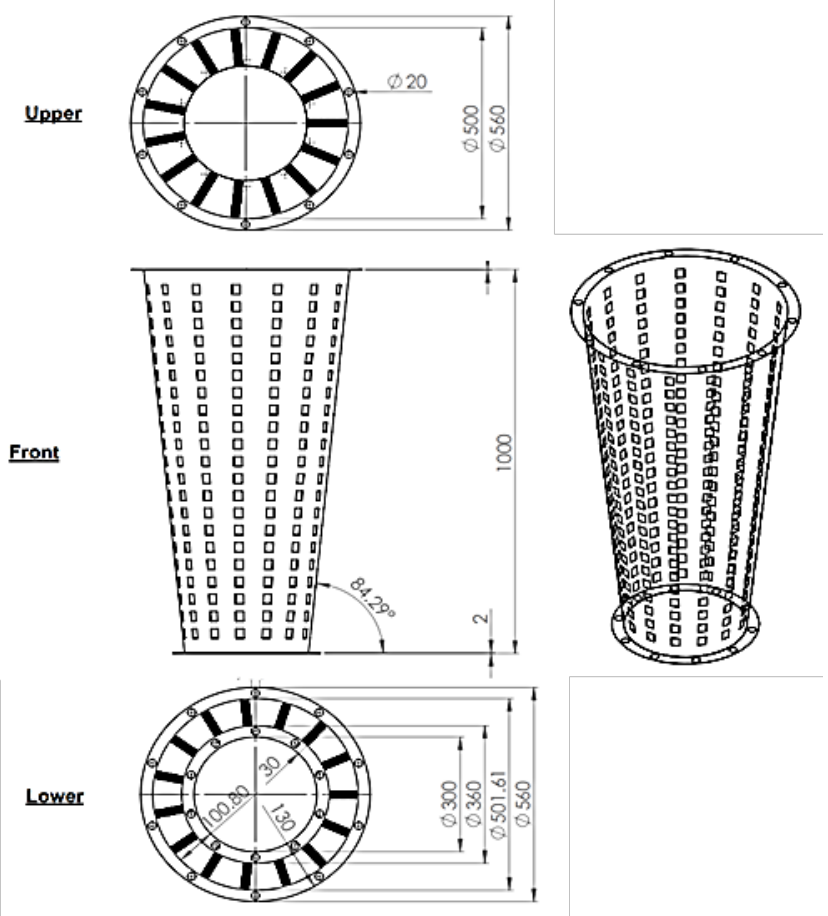

Gambar 3. Desain Casing wire. 
Dimensi casing house adalah panjang casing house $(p) 100 \mathrm{~cm}$, diameter lebar atas $\left(l_{a}\right) 70$ $\mathrm{cm}$, diameter lebar bawah $\left(l_{b}\right) 50 \mathrm{~cm}$. Hasil rancangan desain casing house dan ditunjukkan pada Gambar 4 di bawah ini:
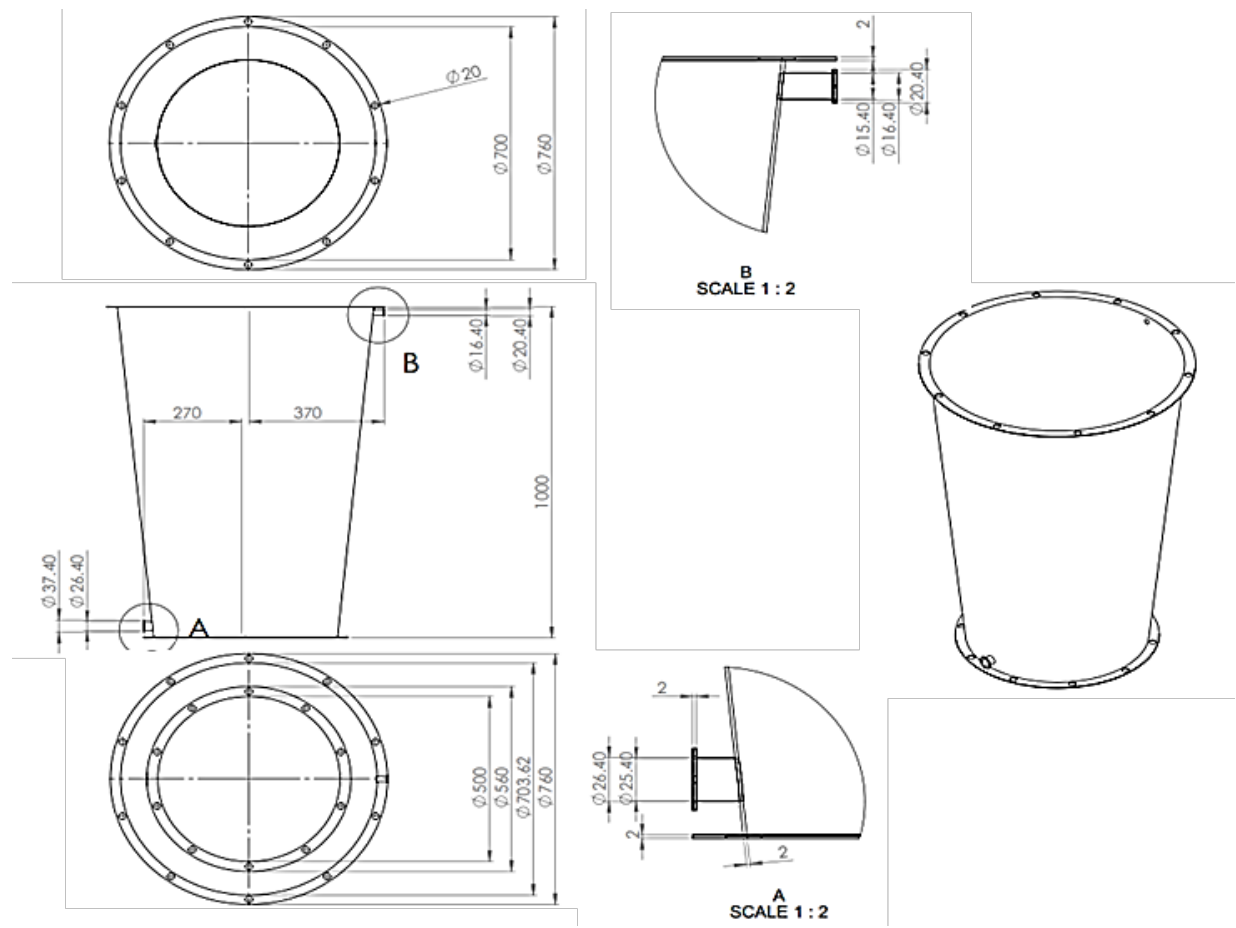

Gambar 4. casing house

\section{Rangka (chassis)}

Dimensi chassis adalah panjang chassis (p) $107 \mathrm{~cm}$, diameter lebar atas $\left(l_{a}\right) 77 \mathrm{~cm}$ dan diameter lebar bawah $\left(l_{b}\right) 77 \mathrm{~cm}$. Hasil rancangan desain casing house dan ditunjukkan pada Gambar 5 di bawah ini:
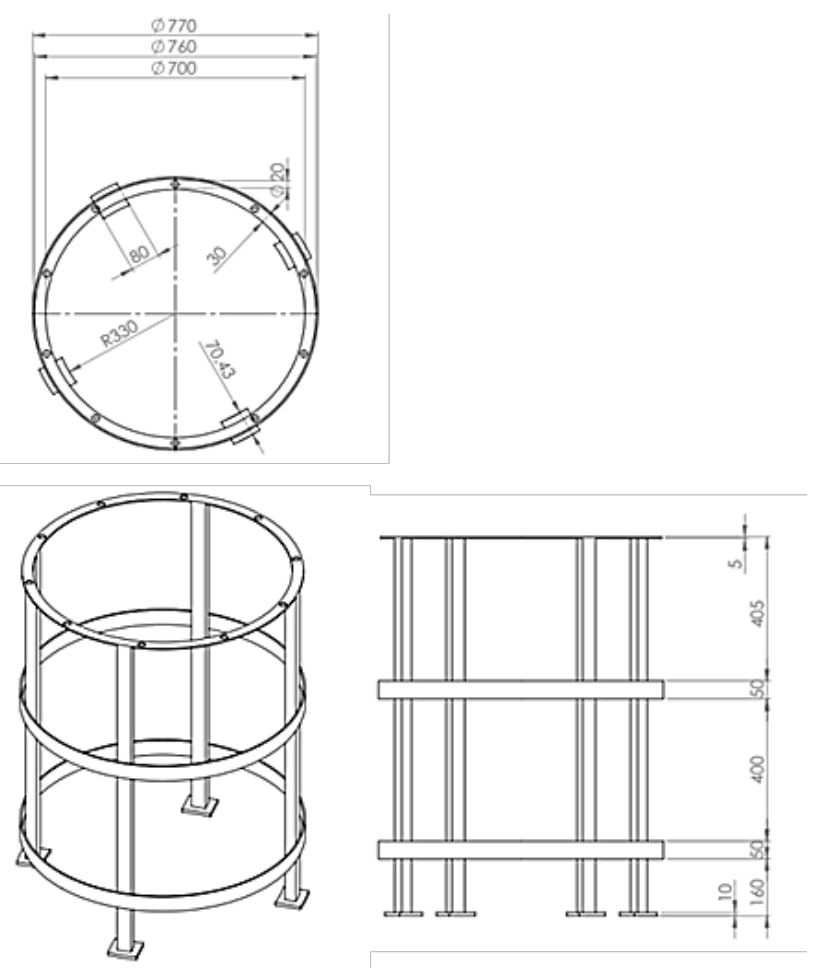

Gambar 5. Chassis. 


\section{Pemilihan material}

Material yang digunakan untuk konstruksi mesin dipilih berdasarkan kekuatan, memiliki sifat penghantar panas yang baik serta mudah dibentuk. Komponen utama yang dirancang meliputi: pengaduk berbentuk Screw, Casing wire dan Casing house menggunakan material dari baja karbon ringan dengan ketebalan $2 \mathrm{~mm}$, sedangkan untuk rangka (chassis) menggunakan material baja karbon kontruksi mesin (JIS G 4501) S35C dengan Kekuatan tarik $52\left(\mathrm{~kg} / \mathrm{mm}^{2}\right)$ [4] dengan ketebalan $3 \mathrm{~mm}$.

Selanjutnya dilakukan uji coba pembuatan prototyping. Prototyping mesin pengering yang telah dibuat ditunjukkan pada Gambar 6 di bawah ini:

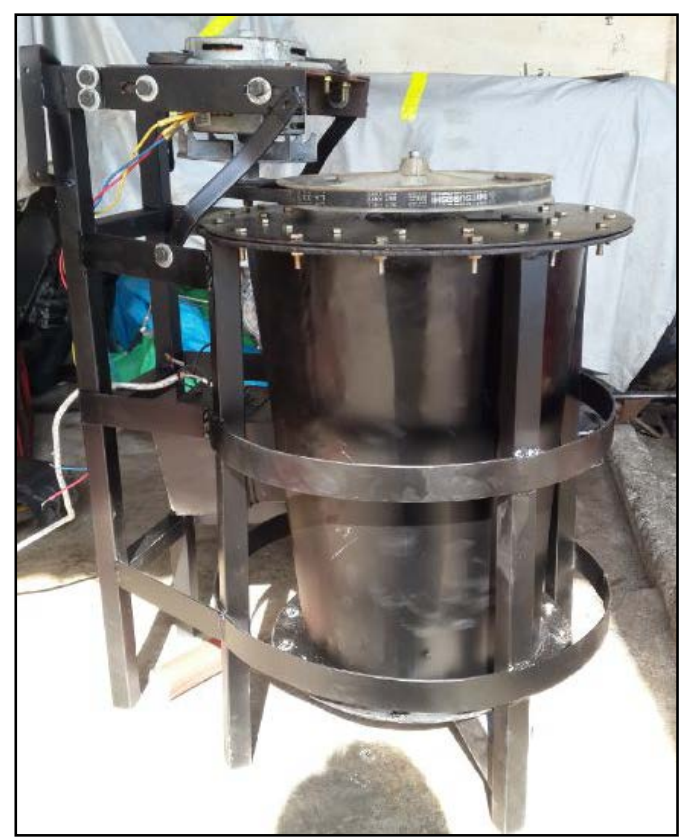

Gambar 6. Prototyping.

\section{SIMPULAN}

Berdasarkan hasil rancang bangun mesin pengering vertikal dengan pengadukan mekanik untuk biji-bijian dapat disimpulkan desain aliran panas masuk (flowin) adalah $0,5 \mathrm{~kg} / \mathrm{m}^{3}$, dan aliran panas keluar (flow out $_{\text {) }}$ adalah $0,52 \mathrm{~kg} / \mathrm{m}^{3}$, Dimensi screw dengan panjang (p) $60 \mathrm{~cm}$, diameter lebar atas $\left(l_{a}\right) 28,8 \mathrm{~cm}$, diameter lebar bawah $\left(l_{b}\right) 22 \mathrm{~cm}$, panjang chassing wire $100 \mathrm{~cm}$, diameter lebar atas $\left(l_{a}\right) 50 \mathrm{~cm}$, diameter lebar bawah $\left(l_{b}\right) 30 \mathrm{~cm}$, panjang chassing house $(p) 100 \mathrm{~cm}$, diameter lebar atas $\left(l_{a}\right) 70 \mathrm{~cm}$, diameter lebar bawah $\left(l_{b}\right) 50 \mathrm{~cm}$ sedangkan panjang chassis $(p) 107 \mathrm{~cm}$, diameter lebar atas $\left(l_{a}\right)$ dan diameter lebar bawah $\left(l_{b}\right) 77 \mathrm{~cm}$. Serta didukung alat bantu berupa: motor listrik yang berfungsi sebagai penggerak pada sistem pengadukan dengan kapasitas 450 rpm putaran motor yang direduksi dengan transmisi sabuk puly. Rancang bangun mesin pengering vertikal dengan pengadukan mekanik telah berhasil dibuat sesuai rancangan.

Saran untuk pengembangan lebih lanjut perlu dipikirkan penggunaan sumber energi alternatif lainnya yang bukan bersumber dari PLN, dimisalkan dengan memanfaatkan biomassa sebagai sumber energi panas agar biaya produksi lebih murah.

\section{DAFTAR PUSTAKA}

[1]. De Padua, Dante B., 1979, Drying in M.Sc. course IPB, Grain Post-Harvest Processing Technology, Pustaka IPB, Bogor.

[2]. Henderson, S.M., and Perry, R.L., 1976, Agricultural Process Engineering, Thrid Edition, The Avi Publishing Company, Inc., Westport, Connecticut. 
[3]. Winarno, F.G., Ferdiez S. dan Fadiaz D., 1980, Pengantar Teknologi Pangan, Gramedia, Jakarta.

[4]. Sularso, Kiyo Katsusuga, 1978, Dasar Pemilihan Dan Perencanaan Mesin, Pradnya Pramita, Jakarta.

[5]. Soedradjat, A., 1983, Mekanika Fluida dan Hidrostatika, Nova, Bandung.

[6]. Kreith Frank, 1991, Prinsip-prinsip Perpindahan Panas, terjemahan Arko Prijono, Penerbit Erlangga, Jakarta.

[7]. Hartanto, Sugiarto, Sato Takeshi, 1992, Menggambar Mesin Menurut Standar ISO, Penerbit PT. Pradya Paramida, Jakarta.

[8]. Reynold, Ton D. Dan Richards, Paul A., 1996, Unit Operations and Processes in Environmental Engineering, 2nd edition, PWS Publishing Company, Boston.

[9]. Mohammad MA et al, 2009, Spin dry-pad: Mesin Pengering Padi Berbasis Sistem Otomasi Untuk Meningkatkan Kualitas produktivitas Padi UD Sumber Rejeki. Institut Teknologi Sepuluh November, Surabaya.

[10]. Pribadyo, dan Zulkifli S., 2016, Perancangan Mesin Pengering Vertikal dengan Pengadukan Mekanik Untuk Biji-bijian, Seminar Nasional Teknologi Rekayasa 3, Politeknik Aceh selatan. 